\title{
Performance Evaluation of Solar Flat Plate Heat Collector with Parallel and Series Flow Configurations
}

\author{
S. Thirumavalavan, Jeeva Bharathi, Manavalan S
}

\begin{abstract}
In view of the warmth move qualities another trial strategy for breaking down the warm presentation of level plate sun powered authority with parallel and arrangement stream examples has been advanced and approved by examinations with the trial and numerical outcomes in previous writing. The proposed trial technique can be utilized to examine and talk about the impact of important parameters on the warm exhibition of level plate sunlight based gatherer.
\end{abstract}

\section{Keywords : Trial strategy, Parallel stream}

\section{INTRODUCTION}

Sunlight based vitality is a significant, spotless, modest and copiously accessible sustainable power source. It is gotten on Earth in cyclic, discontinuous and weaken structure with low control thickness 0 to $1 \mathrm{kw} / \mathrm{m} 2$.Solar vitality got on the ground level is influenced by barometrical lucidity, level of scope, and so on. For plan purpose, the variety of accessible sun oriented power, the ideal tilt edge of sun powered level plate authorities, the area and direction of the heliostats ought to be determined[19],[21],[22].

A sun based warm authority framework assembles the warmth from the sun powered radiation and offers it to the warmth transport liquid. The warmth transport liquid gets the warmth from the gatherer and conveys it to the warm capacity tank, heater steam generator, heat exchanger and so forth. Warm capacity framework stores heat for a couple of hours. The warmth is discharged during shady hours and around evening time. Warm electric transformation framework gets warm vitality and drives steam turbine generator or gas turbine generator[14],[16],[18]. The electrical vitality is provided to the electrical burden or to the AC framework. Uses of sun based warm vitality frameworks extend from basic sunlight based cooker of $1 \mathrm{KW}$ rating to complex sun oriented focal beneficiary warm power plant of 200 MWrating.

As sun based power has low thickness $(\mathrm{kw} / \mathrm{m} 2)$, in this way huge zone on the ground is secured by gatherers. Level plate gatherers are utilized for low temperature applications.

Revised Manuscript Received on August 22, 2019.

S. Thirumavalavan, Department of Mechanical Engineering, Bharath Institute of Higher Education and Research, Chennai, Tamilnadu, India. Email: thiru_thiru@hotmail.com

Jeeva Bharathi, Department of Mechanical Engineering, Bharath Institute of Higher Education and Research, Chennai, Tamilnadu, India. Email: jeevabharathi013@gmail.com

Manavalan S, Department of Mechanical Engineering, Bharath Institute of Higher Education and Research, Chennai, Tamilnadu, India.

Email: manavalan.kannan@gmail.com
For accomplishing higher temperature of vehicle liquid, the sun beams must be thought and centered.

\section{CONCEPT OF BLACK BODY}

A dark body is characterized as an ideal producer and safeguard of radiation. At a predetermined temperature and wavelength, no surface can emanate or ingest more vitality than a dark body. A dark body is a diffuse producer which means it transmits radiation consistently toward all path. Additionally a dark body assimilates all episode radiation paying little mind to wavelength and bearing. As such dark body is a romanticized physical body that retains all occurrence electromagnetic radiation, paying little respect to recurrence or edge of rate.

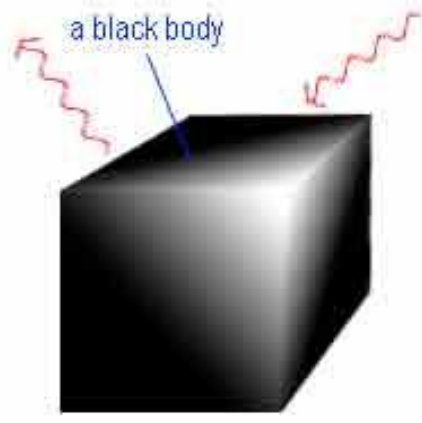

Figure 1 Black Body

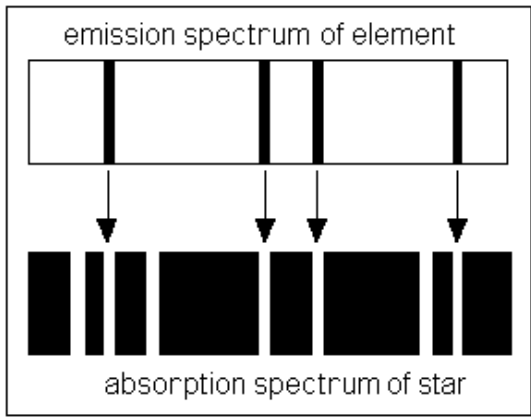

Figure - 2 Black body emission

\section{PARALLEL CONFIGURATION}

Most level plate gatherer has little parallel cylinders associated with a bigger fundamental transporter pipes as appeared in Figure[13],[15],[17]. These little parallel cylinders are called riser tubes since this is the place the working liquids would ascend so as to collect the warmth from the sun.

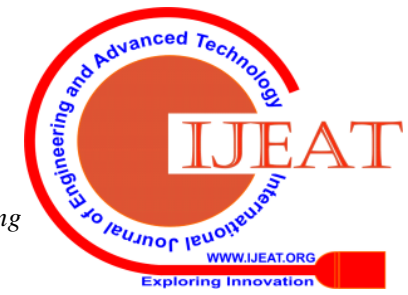


The parallel cylinder is intended to move working liquid from the base of the level plate gatherer to the highest point of the level plate authority. The liquids weight is higher at the base of the gatherer and least at the top.

On the off chance that the top and base funnels are huge, the weight contrast is directed and the stream rate in every one of the parallel channels is increasingly uniform .Unfortunately, the stream rate is negligible at the inside where the greater part of the warmth is concentrated[8],[10],[12]. One little break can cause disastrous chaos in experimentation and computation.

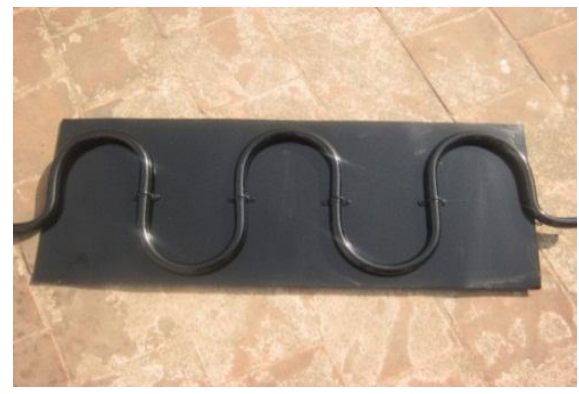

Figure 3 - Parallel configuration

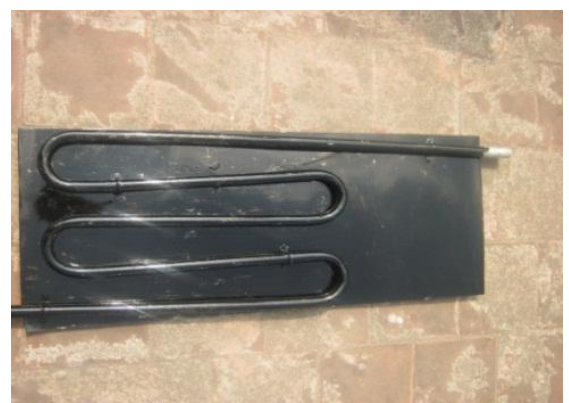

Figure - 4 Series Configuration

\section{SERIES CONFIGURATION}

The arrangement stream in Figure beneath comprises of one long consistent adaptable cylinder so there is no issue with uniform stream rate. The working liquids stream consistently from base to the highest point of the authority. This outcomes in consistent warmth move from the warmth safeguard to the working liquid. Since the stream pace of the liquid through the arrangement cylinder is uniform the warmth accumulation procedure is uniform. The size of this adaptable tubing is a significant thought. The regular size utilized for tubing is 3/8 creeps of distance across[7], [9],[11].

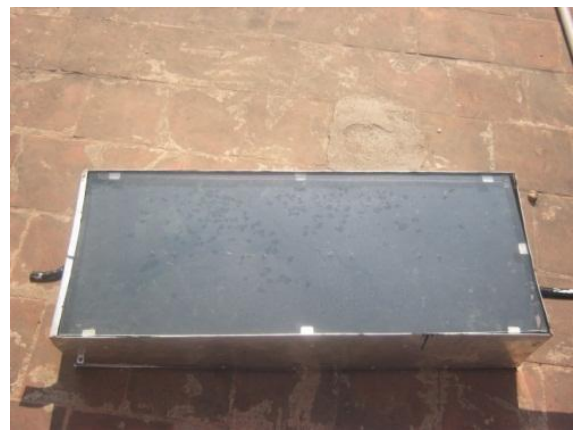

Figure - 5 experiment with parallel flow configuration

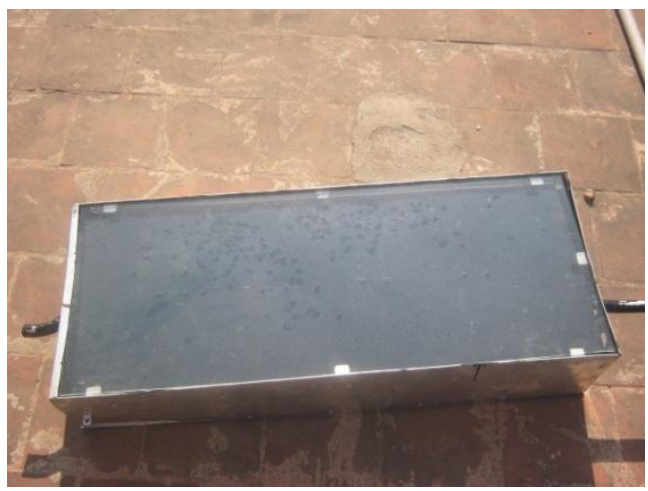

Figure 6 - Experiment with series flow configuration

\section{WORKING OF PARALLEL FLOW}

1. The project placed in open area so that sun radiation is possible to reach up to the heat exchanger system.

2. As the system is provide the inlet connector to connect the inlet and the water source, the water is supplied from the source to inlet.

3 . The plate and the tube is painted with black colour will absorb the solar radiation from the surrounding.

4. The water from the source flows through the $U$ bend aluminum tube .The tube and the plate will transfer the heat absorbed from the sun to the water.

5. The toughened glass is used to increase intensity of the solar radiation and to reduce heat loss from the system to the surrounding.

6. The outlet water is obtained with some temperature difference, as the result of heat exchanger process.

7. The acquired temperature difference is found using the thermometer and noted for the calculation purpose.

8 . Take the reading of temperatures of Ti , Teof parallel flow configuration.

9. After testing the parallel flow set up remove the parallel flow pattern from the case and insert the series flow pattern.

\section{WORKING OF SERIES FLOW}

1. The project placed in open area so that sun radiation is possible to reach up to the heat exchanger system.

2. As the system is provide the inlet connector to connect the inlet and the water source, the water is supplied from the source to inlet.

3 . The plate and the tube is painted with black colour will absorb the solar radiation from the surrounding[2],[4],[6].

4. The water from the source flows through the $U$ bend aluminum tube. The tube and the plate will transfer the heat absorbed from the sun to the water.

5. The toughened glass is used to increase intensity of the solar radiation and to reduce heat loss from the system to the surrounding.

6. The outlet water is obtained with some temperature difference, as the result of heat exchanger process.

7. The acquired temperature difference is found using the thermometer and noted for the calculation purpose.

8. Take the reading of temperatures of $T_{i}, T_{e}$ of series flow configuration [1],[3],[5] .

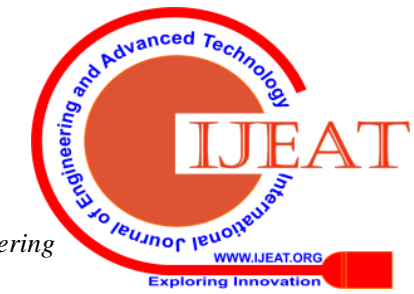


9. After testing the series flow set up remove the parallel flow pattern from the case and insert the parallel flow pattern.

\section{CONCLUSION}

The concept discussed here is to increase the heat transfer rate by the idea of parallel and series flow patterns. Due to this heat transfer gets increased through the parallel flow configuration comparing with series flow configuration. In parallel flow pattern we get large amount of water in output compare to series flow pattern. The mass flow rate and the the flat plate efficiency is higher than series flow configuration in parallel flow configuration Essential relations that are needed for further analysis has also been shown in this project report where focus has been on the mass flow rate equations.

\section{REFERENCES}

1. Tatikonda, N.C. \& Naveenchandran, P. 2019, "The behaviour of a compression ignition engine under the influence of diesel and microalgae biodiesel blends", International Journal of Mechanical and Production Engineering Research and Development, vol. 9, no. 4, pp. 447-456.

2. Tatikonda, N.C. \& Naveenchandran, P. 2019, "An experimental assessment on the impact of injection pressure on the characteristics of a diesel engine powered with the blend of diesel and microalgae biodiesel", International Journal of Engineering and Advanced Technology, vol. 8, no. 6, pp. 3284-3291.

3. Karthikeyan, S., Raman Balasubramanian, S.R., Ramesh, B., Raghul, S. \& Sathish Kumar, S. 2019, "The automatic solar tracker chronicles", International Journal of Recent Technology and Engineering, vol. 8, no. 1, pp. 312-315.

4. Hema, R., Sundararajan, M. \& Balaji, S. 2019, "Smartphone control robot with automatic firing gun", International Journal of Innovative Technology and Exploring Engineering, vol. 8, no. 9 Special Issue 3, pp 625-627.

5. Saritha, B., Chockalingam, M.P. \& Aswathy, M. 2019, "Degradation of anionic dye using $\mathrm{Fe} / \mathrm{Tio} 2$ composite by photocatalysis", International Journal of Innovative Technology and Exploring Engineering, vol. 8, no. 9 Special Issue 3, pp. 788-791.

6. Saritha, B., Maria Subashini, L. \& Aswathy, M. 2019, "Utilization of spent coffee grounds for compost production", International Journal of Innovative Technology and Exploring Engineering, vol. 8, no. 9 Special Issue 3, pp. 908-910.

7. Fernando, J.K., Meikandaan, T.P. \& Hemapriya, M. 2019, "Better utilisation of bottom ash in coal fired thermal power station", International Journal of Innovative Technology and Exploring Engineering, vol. 8, no. 9 Special Issue 3, pp. 898-900.

8. Kumar, K.S., Kiruthiga, K. \& Thendral, S. 2019, "Experimental analysis on fractional substitution of bond by utilizing rice husk cinder", International Journal of Innovative Technology and Exploring Engineering, vol. 8, no. 9 Special Issue 3, pp. 1163-1165.

9. Vignesh, P., Madan, P., Mohankumar, D. \& Naveenchandran, P. 2019, "Optimization of four stroke c.i. engine performance by using statistical techniques (mathematical method)", International Journal of Recent Technology and Engineering, vol. 8, no. 2, pp. 1685-1691.

10. Bharanidharan, S., Sathiyamurthy, K. \& Sheeba, B. 2019, "Using co-precipitation method determining synthesis and characterization of fe doped zinc oxide nanoparticles", International Journal of Innovative Technology and Exploring Engineering, vol. 8, no. 9 Special Issue 3, pp. 705-707.

11. Jeevanandan, D. \& Vino, J.A. 2019, "Heat recovery from boiler blowdown water by using heat exchanger in thermal power plant", International Journal of Mechanical and Production Engineering Research and Development, vol. 9, no. 3, pp. 219-222.

12. Rakesh, N.L., Balambica, V. \& Kannan, S. 2019, "Biogas extraction from waste orange peel by digestion process", International Journal of Mechanical and Production Engineering Research and Development, vol 9, no. 3, pp. 323-330.

13. Meenakshi, C.M. \& Krishnamoorthy, A. 2019, "The mechanical characterization of mono and hybrid fiber reinforced composites using experimental and finite element analysis methods", International Journal of Mechanical and Production Engineering Research and Development, vol. 9, no. 3, pp. 189-196.

14. Mohankumar, D., Prem Jayakumar, M., Sabarsish, R. \& Naveen Chandran, P. 2019, "Modeling and experimental investigation on centrifugal blower by computational fluid dynamics", International Journal of Mechanical and Production Engineering Research and Development, vol. 9, no. 3, pp. 331-340.

15. Balambica, V., Deepak, V. \& Kumar, S. 2019, "Design and efficiency of an asymmetric gear", International Journal of Mechanical and Production Engineering Research and Development, vol. 9, no. 3, pp. 223-230.

16. Manavalan, S., Balakrishnan, G. \& Ramasubramaniam, S. 2019, "An effect of cobalt oxide nano additive with biodiesel blends using cidi diesel engine", International Journal of Mechanical and Production Engineering Research and Development, vol. 9, no. 3, pp. 211-218.

17. Golden Renjith Nimal, R.J., Sivakumar, M. \& Esakkimuthu, G. 2019, "An investigation on mechanical properties and microstructure of mg/al alloys using zn interlayer during diffusion bonding", International Journal of Mechanical and Production Engineering Research and Development, vol. 9, no. 3, pp. 125-130.

18. Hariharan, R., Raja, R. \& Vasu, S. 2019, "Mechanical and tribological behaviour of thin tan coating produced on AISI 1018 substrate by DC magnetron sputtering", International Journal of Recent Technology and Engineering, vol. 7, no. 6, pp. 591-598

19. Manavalan, S., Rai, R., Kumar, R.R., Chaudhary, R.K. \& Chaudhary, S.K. 2019, "Impact of modified piston - A review", International Journal of Recent Technology and Engineering, vol. 8, no. 6, pp. 616-620.

20. Manavalan, S., Gopi, A., Arivarasu, J., Abishek Ahi, A. \& Chandru, S. 2019, "Review on ceramic disc brake system", International Journal of Recent Technology and Engineering, vol. 7, no. 6, pp. 612-615.

21. Sabarish, R. \& Jeya Kumar, M.P. 2019, "The design and analysis of piston - Steady state thermal analysis using "ansys"", International Journal of Mechanical and Production Engineering Research and Development, vol. 9, no. 3, pp. 197-204.

22. Ravi, D. 2019, "CFD simulation of solar loading in car", International Journal of Mechanical and Production Engineering Research and Development, vol. 9, no. 3, pp. 231-236.

\section{AUTHORS PROFILE}

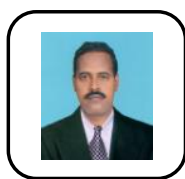

S. Thirumavalavan Assistant Professor, Departmen of Mechanical Engineering, Bharath Institute of Higher Education and Research, Chennai, India.

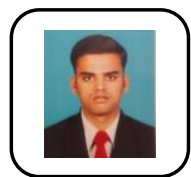

Jeeva Bharathi Assistant Professor, Department of Mechanical Engineering, Bharath Institute of Higher Education and Research, Chennai, India.

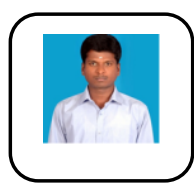

Manavalan S Assistant Professor, Department of Mechanical Engineering, Bharath Institute of Higher Education and Research, Chennai, India. 